\title{
«...YO ASÍ, LOCOS COMO LOS VI A USTEDES, NO ME LO IMAGINABA.» LAS IMÁGENES DE CIENCIA Y DE CIENTÍFICO DE ESTUDIANTES DE CARRERAS CIENTÍFICAS
}

\author{
Mengascini, Adriana ${ }^{1}$; Menegaz, Adriana ${ }^{1}$; Murriell o, Sandr a ${ }^{1}$ y Pet rucci, Diego ${ }^{2}$ \\ Grupo de Didáctica de las Ciencias. La Plata. Argentina \\ ${ }^{1}$ Facultad de Ciencias Naturales y Museo. Universidad Nacional de La Plata \\ ${ }^{2}$ Instituto de Desarrollo Humano. Universidad Nacional de General Sarmiento y Centro de Formación e Investigación en Ense- \\ ñanza de las Ciencias, FCEN. Universidad de Buenos Aires \\ gdc@isis.unlp.edu.ar
}

\begin{abstract}
Resumen. Este trabajo presenta un estudio sobre las imágenes de ciencia y de científico de estudiantes de licenciaturas en ciencias naturales. Se analizan las implicaciones de sus representaciones en relación con una futura inserción en el campo científico. La definición de categorías para el análisis cualitativo se realizó en función de los mismos datos, procesados previamente según la semiótica de enunciados. Tanto el marco teórico como la metodología empleada constituyen aportes originales al estudio de imágenes de ciencia en contextos educativos. Asimismo se pretende que las reflexiones emergentes sirvan como una contribución para el análisis crítico de las prácticas de enseñanza y aprendizaje.

Palabras clave. Imagen de ciencia, imagen de científico, representación social, estudiantes universitarios.
\end{abstract}

Summary. We present a study about the image of science and scientists among natural sciences students at university level. The connection between the consequences of such representations and their future insertion in the scientific field are also analysed. Defining the categories for a qualitative analysis was done based on the data that had been previously processed as per the semiotics of the statements. Both the theoretical framework and the methodology used can be considered original contributions to studies about the image of science in educational contexts. The resulting reflections will also be used in a critical analysis of teaching and learning activities.

Keywords. Image of science, image of scientists, social representation, university students.

\section{INTRODUCCIÓN}

Las imágenes de ciencia en los contextos de enseñanza $\mathrm{y}$ aprendizaje han sido objeto de estudio de numerosas investigaciones en didáctica de las ciencias en las últimas décadas (Driver et al., 1996; Lederman, 1992; Lederman et al., 1998). Los estudios, desarrollados desde diferentes enfoques y metodologías, a menudo presentan sus resultados asociando las imágenes de los estudiantes a categorías derivadas de corrientes epistemológicas (Kouladis y Ogborn, 1989). Este artículo es producto de la continuación de un estudio (Petrucci y Dibar Ure, 2001) que revisa el estado del conocimiento del tema y que efectúa aportaciones relevantes sobre las imágenes de ciencia de los alumnos universitarios.

En la Facultad de Ciencias Naturales y el Museo de la
Universidad Nacional de La Plata se imparten las carreras científicas de Biología (con cuatro orientaciones: Botánica, Ecología, Paleontología y Zoología), Geología y Antropología. La propuesta de formación está orientada tanto hacia la práctica de la investigación como hacia la actividad en el ámbito académico y profesional, con especial énfasis en la primera. En coincidencia con esta oferta formativa, cabe señalar que un $75 \%$ de los ingresantes a la institución manifiesta, entre sus expectativas, la práctica de la investigación como salida laboral (DDCN, 1994). Los docentes mismos son, en su mayoría, investigadores. Sin embargo, los planes de estudio no incluyen espacios curriculares específicos relacionados con la epistemología. 
Nuestro objetivo es caracterizar y analizar las imágenes de los estudiantes inmersos en este contexto de formación a fin de indagar, por un lado, cómo plantean su relación con la ciencia y cuál es su proyección como investigadores y, por otro, reflexionar respecto de los factores que pueden haber influido en el desarrollo de dichas imágenes. El trabajo presenta la descripción y definición de estas imágenes a partir del discurso de los estudiantes, el análisis de estos resultados -que se discuten considerando trabajos preexistentes- y las reflexiones finales sobre el valor que revisten en el contexto de formación.

\section{ASPECTOS TEÓRICOS Y METODOLÓGICOS}

El enfoque metodológico empleado es de tipo exploratorio y tanto los datos como su tratamiento son cualitativos (Glasser y Strauss, 1968; Erickson y Nosanchuk, 1977).

\section{Diseño del instrumento y caracterización de los estudiantes}

La recolección de la información se realizó por medio de entrevistas semiestructuradas. El instrumento fue diseñado teniendo en cuenta tres cuestiones: la revisión bibliográfica, nuestros supuestos -que habían sido explicitados al inicio de la investigación- y algunos aspectos surgidos de resultados previos comunicados por Petrucci y Dibar Ure (2001). Dichos resultados fueron obtenidos mediante un cuestionario que incluía preguntas abiertas y cerradas sobre las imágenes de ciencia de los estudiantes de la Universidad Nacional de La Plata y la Universidad de Buenos Aires.

El instrumento fue puesto a prueba mediante una entrevista inicial, cuyos resultados fueron analizados y comparados con los del cuestionario. Se decidió que el diseño era apropiado debido a que brindaba información relevante con relación a nuestros objetivos. Posteriormente fueron entrevistados 4 estudiantes más, de segundo año de la facultad, hacia fines del año 1996. Los 5 estudiantes cursaban la licenciatura en Biología (dos con orientación en Zoología, dos en Ecología y uno en Paleontología) y formaban parte de la población que había respondido el cuestionario.

Fueron utilizados también algunos datos (Tabla I) tomados de otras entrevistas realizadas en 1998 para otro estudio. En ella se empleó un guión diferente, aunque tenía puntos en común con el anterior. Los 5 estudiantes entrevistados se encontraban también cursando segundo año de la licenciatura en Biología (tres con orientación en Zoología, uno en Ecología y uno en Paleontología).

Todos los estudiantes tenían una formación previa común. Durante el primer año habían cursado las asignaturas de Zoología General, Fundamentos de Geología, Introducción a la Botánica, Matemática y Química
General. Al momento de ser entrevistados acababan de cursar las materias de segundo año: Química Orgánica, Física General, Estadística, Introducción a la Taxonomía, Morfología Vegetal (sólo para Ecología), Histología y Embriología Animal (sólo para Zoología), Fundamentos de Paleontología y Ecología General (estas dos últimas sólo para Paleontología).

En todos los casos, los estudiantes fueron elegidos al azar. En el anexo se presentan aquellas preguntas de ambas entrevistas cuyas respuestas fueron utilizadas en este estudio. Las restantes preguntas forman parte de un estudio exploratorio para una tesis de postgrado.

\section{Análisis de las entrevistas}

El análisis se inició a partir de la lectura y relectura de las entrevistas completas. Posteriormente decidimos centrarnos en las imágenes de «ciencia», «científico» y «conocimiento científico».

La metodología empleada para el análisis de las entrevistas fue la semiótica de enunciados (Magariños de Morentín, 1993, 1996). Esta herramienta «permite la identificación de las relaciones semánticas efectivamente utilizadas en un corpus de textos resultantes de la transcripción y reescritura de discursos recolectados en el trabajo de campo, constituyendo un aporte para el tratamiento cualitativo de la información en investigaciones sociales» (Ceirano, 2000, p. 8). De este modo es posible establecer el contenido semántico de los conceptos correspondientes a los términos utilizados en las entrevistas.

Las operaciones seguidas en el proceso fueron: normalización y segmentación del texto, elaboración de definiciones contextuales y construcción de ejes conceptuales. En el cuadro I se presenta un ejemplo del proceso efectuado a partir de un fragmento de entrevista.

1) Normalización y segmentación: El primer tratamiento que efectuamos sobre el texto de la entrevista fue la normalización, que consistió en recuperar o completar construcciones sintácticas omitidas en relación con la economía del habla. En este procedimiento no se impuso ningún modelo de corrección prefijado por una gramática normativa (Ceirano, 2000). Estas operaciones se señalan en el texto normalizado por medio de paréntesis cuando se refieren a la explicitación de un sujeto sintáctico tácito. En estos casos se agrega un signo igual (=) al principio o al final del paréntesis, según que el término recuperado se encuentre antes o después en el texto original. Las aclaraciones que efectuamos durante el tratamiento del texto se indicaron entre corchetes.

Las partes básicas o elementales del texto fueron segmentadas según un criterio sintáctico. En el texto normalizado estas oraciones de base fueron separadas mediante asteriscos $(*)$. El proceso de segmentación se completó desglosando el texto en las oraciones de base. 


\section{Fragmento de entrevista}

Entrevistador: Quiero que describas cómo te imaginás vos, tu imagen de cómo trabaja un científico.

Alumna: ¿De cómo trabaja?

Entrevistador: Sí.

Alumna: Ay, no sé, me lo imagino todo el tiempo encerrado... en un laboratorio, y dándole, dándole, dándole, hasta que llega a algo, descubre algo o, que sé yo, ve sobre ya, sobre lo descubierto, cosas. No sé, me lo imagino trabajando todo el tiempo.

\section{Normalización y segmentación}

* ¿De cómo trabaja (= un científico) $*$ *Ay no sé (= cómo trabaja [= un científico]) *[a] (= un científico) me lo imagino todo el tiempo encerrado en un laboratorio *y dándole, dándole, dándole, hasta que llega a algo *descubre algo * o... o que sé yo *ve sobre ya *(= ve) $(\operatorname{cosas}=)$ sobre lo (= ya) descubierto *no sé *[a] (= un científico) me lo imagino trabajando todo el tiempo*

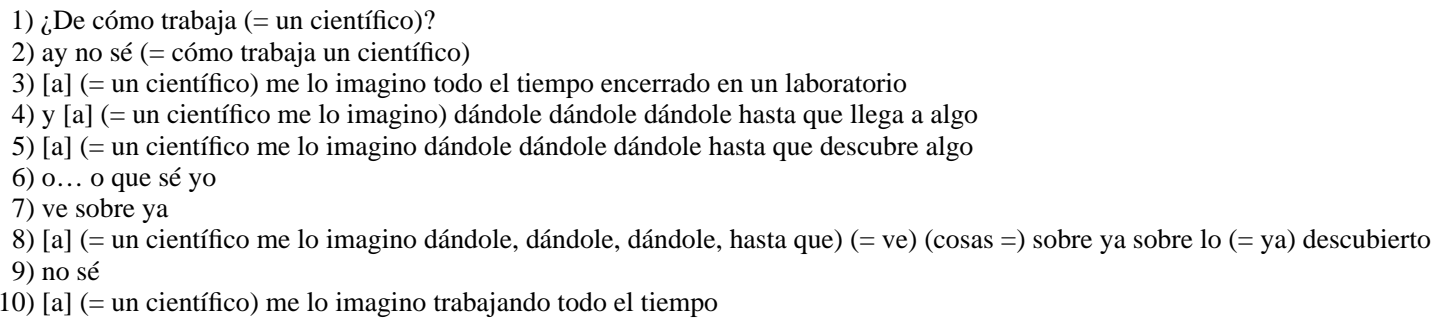

Elaboración de definiciones contextuales

3) CIENTÍFICO es aquél que me lo imagino todo el tiempo encerrado en un laboratorio.

4) CIENTÍFICO es aquél que me lo imagino dándole dándole dándole hasta que llega a algo.

5) CIENTÍFICO es aquél que me lo imagino dándole dándole dándole hasta que descubre algo.

8) CIENTÍFICO es aquél que me lo imagino dándole dándole dándole hasta que ve cosas sobre lo ya descubierto.

10) CIENTÍFICO es aquél que me lo imagino trabajando todo el tiempo.

2) Elaboración de definiciones contextuales: A través de las definiciones contextuales fue establecido el sentido de los términos seleccionados en función del contexto al cual dicho término aparecía asociado en el mismo segmento (Magariños de Morentín, 1993). En la definición contextual resultante, el término objeto de análisis se encuentra vinculado al resto de la oración por medio de una expresión preposicional del tipo: es aquél que / es aquello con lo que / es aquello en el que / es aquél para que /, etc. El resultado obtenido es un «diccionario» con los valores semánticos que el sujeto le confirió al término en su discurso. En el ejemplo presentado en el cuadro I, los segmentos 1, 2, 6, 7 y 9 fueron descartados debido a que los consideramos como expresiones coloquiales, propias del lenguaje hablado, que no aportaban nada al significado de los términos analizados.

3) Construcción de ejes conceptuales: La construcción de ejes conceptuales se efectuó a través de la categorización de las definiciones contextuales obtenidas, realizada en función de sus similitudes o reiteraciones semánticas. Mediante sucesivas lecturas y reagrupamientos, las categorías se fueron delineando a partir de los mismos datos, minimizando nuestras interpretaciones.

\section{Elaboración de las reflexiones emergentes}

Para la elaboración de las reflexiones emergentes, en un proceso de metaanálisis de los resultados, recurrimos al concepto de representación social. A nuestro entender, este concepto trasciende los alcances de términos como imagen, visión, noción, concepción o idea, remitiéndonos a un marco teórico particular de la sociología y la psicología social.

En el marco de la psicología cognitiva, el concepto de $r e$ presentación alude a un producto de la selección y categorización de información llevada a cabo por los sujetos en la construcción de saberes y en la comprensión de su entorno. En esta actividad cognitiva, el sujeto privilegia ciertas propiedades de los objetos cognoscibles sobre otras, en una simplificación que acentúa diferencias y semejanzas. Este filtro obedece a diversos factores, inherentes tanto al sujeto como al contexto social. El resultado es una representación «desequilibrada», con elementos centrales sólidamente organizados en un núcleo y elementos periféricos no vinculados entre sí (Guichard, 1995). Este proceso es eminentemente simbólico, ya que la representación puede considerarse como una sustitu- 
ción, aludiendo a una interpretación y conformando un sistema referencial (Ceirano, 2000). La representación implica una relación establecida por un individuo que pertenece a un grupo determinado con una realidad que él mismo interpreta. Es un reflejo tanto del objeto como de la actividad del sujeto que lo conoce: el sujeto es un actor, un constructor (Guichard, 1995).

Jodelet (1986), desde la psicología social, define las representaciones sociales como imágenes no especulares que implican una relación sujeto-objeto, cargadas de valores y sentidos generados en el seno de distintos grupos sociales. Condensan significados y se constituyen en sistemas de referencia que nos permiten interpretar y clasificar circunstancias, fenómenos, individuos con los que interactuamos.

Desde una perspectiva sociológica, al analizar las representaciones, se consideran, principalmente, las relaciones de poder entre grupos sociales que operan en torno a la estructuración de esquemas mentales. Según algunas corrientes sociológicas, la actividad representativa se basa en la reproducción de esquemas de pensamiento socialmente establecidos y en visiones estructuradas por ideologías dominantes (Jodelet, 1986). Para Bourdieu (1991), las representaciones se estructuran a través de un habitus, al cual define como sistemas de disposiciones para actuar, percibir, valorar, sentir y pensar de una cierta manera más que de otra. Estas disposiciones durables y transferibles, interiorizadas por el individuo en el curso de su historia, pueden expresarse en términos de lo pensable y lo no pensable, lo que es para nosotros y lo que no lo es, lo posible y lo no posible. El habitus hace posible la producción «libre» de todos los pensamientos, acciones, percepciones, expresiones siempre que estén inscriptas en los límites inherentes a las condiciones particulares de su producción (Gutiérrez, 1995).

En Las palabras y las cosas, Foucault (1998) cita un texto de Borges en el que aparece «cierta enciclopedia china... [según la cual]... los animales se dividen en: $a$ ) pertenecientes al emperador, $b$ ) embalsamados, $c$ ) amaestrados, d) lechones, $e$ ) sirenas, $f$ ) fabulosos, $g$ ) perros sueltos, $h$ ) incluidos en esta clasificación, $i$ ) que se agitan como lo$\cos , j$ ) innumerables, $k$ ) dibujados con un pincel finísimo de pelo de camello, $l$ ) etcétera, $m$ ) que acaban de romper el jarrón, $n$ ) que de lejos parecen moscas» ${ }^{1}$. Foucault (1998) dice al respecto de este texto que «lo que se ve de golpe, lo que, por medio del apólogo, se nos muestra como encanto exótico de otro pensamiento, es el límite del nuestro: la imposibilidad de pensar esto». Inmediatamente pregunta: «¿Qué es imposible pensar y de qué imposibilidad se trata?»

Teniendo en cuenta lo expresado precedentemente, nosotros nos preguntamos en el contexto particular de nuestro análisis: ¿qué representaciones de ciencia y de científico están presentes en los discursos de los estudiantes? Y por ende: ¿qué ciencia y qué científico son imposibles de ser pensados?

\section{RESULTADOS}

Como puede apreciarse en la tabla I, el grueso de los datos fue tomado de las entrevistas realizadas en 1996, mientras que las de 1998 aportaron datos para elaborar casi exclusivamente definiciones contextuales de ciencia.

Se detallan a continuación los resultados obtenidos en relación con las imágenes de científico, ciencia y conocimiento científico. Los subtítulos (entre comillas) corresponden a las categorías que hemos elaborado. Entre paréntesis se citan las definiciones contextuales construidas. En algunos casos hemos considerado más apropiado citar textualmente frases o fragmentos de las mismas.

\section{El científico}

En sus discursos, los estudiantes caracterizan al científico en relación con su preparación, su trabajo y su ética. En algunos casos es posible identificar una oposición entre imágenes: el «científico típico» $\mathrm{o}$ «de antes» y una nueva imagen relacionada con la vivencia en el ámbito académico.

Según los estudiantes, el trabajo de un científico consiste en dedicarse a buscar (Cien t íf ico es aquél que está constantemente buscando explicaciones a algo / es aquél que busca el porqué de algo / es aquél que busca porque le interesa algo / es aquél que busca el porqué de las cosas); investigar y pensar (Cien t íf ic o es aquél que se ocupa de pensar un porqué / es aquél que la mayor parte de su trabajo debe ser pensar / es aquél que piensa hipótesis / es aquél que está obligado a pensar y a contrastar una hipótesis).

Tabla I

C antidad de definiciones contextuales elaboradas.

\begin{tabular}{|l|c|c|c|}
\hline \multirow{2}{*}{ Definiciones contextuales } & \multicolumn{2}{|c|}{ Año } & \multirow{2}{*}{ Total } \\
\cline { 2 - 3 } & $\mathbf{1 9 9 6}$ & $\mathbf{1 9 9 8}$ & \\
\hline Científico & $84(97 \%)$ & $3(3 \%)$ & 87 \\
\hline Ciencia & $110(64 \%)$ & $61(36 \%)$ & 171 \\
\hline Conocimiento científico & $31(100 \%)$ & $0(0 \%)$ & 31 \\
\hline Total & $\mathbf{2 2 5}(\mathbf{8 8 \%})$ & $\mathbf{6 4}(\mathbf{2 2 \%})$ & $\mathbf{2 8 9}$ \\
\hline
\end{tabular}


Con respecto a la formación afirman que un científico es: aquél que estudió y se preparó para eso; un tipo mucho más preparado; uno que tiene medios para poder investigar; trabaja manejando mucha más información que el resto.

El trabajo de un científico es metódico y riguroso (Cien t ífico es aquél que va a seguir ciertos pasos / es aquél que integra muchas cosas / es aquél que trabaja contrastando esa hipótesis con otra y rechazándola / es aquél que tiene que hacer un montón de pruebas), aunque no exento de subjetividad (Cien $t$ íf ic o es aquél que tiende más a refutar lo ajeno porque lo de uno es de uno / es aquél que aprueba que un conocimiento sea científico formal si tiene sustento lógico porque es lógico para él).

El científico tiene una ética: es desinteresado, lo mueve su ansia de saber, no manipula (Cien $t$ íf ic o es aquél que no usa a la ciencia / es aquél que apunta a mejorar las cosas / es aquél que quiere mejorar desde la producción de leche de una vaca hasta la realización de un trabajo), aunque puede ser manipulado. El siguiente párrafo textual ejemplifica claramente esta visión:

«Me parece que a la ciencia en muchos momentos la usaron. Fue usada por política, en casos de guerra. Pero me imagino que el científico no, el científico siempre trató de progresar y hacer lo mejor posible en lo suyo, porque le interesaba.»

\section{El típico científico que te pintan en todos lados}

Una de las imágenes que aparece entre los entrevistados es la que denominamos científico típico, que es una especie de científico loco, al que califican como: viejo, «re-estricto», con anteojos y con guardapolvo; un tipo aislado, encerrado, metido ahí en lo que hace, de laboratorio, tipo Anteojito ${ }^{2}$.

Este personaje se encuentra siempre en su laboratorio, con un microscopio o algún aparato (Cient ífico es aquél que está trabajando todo el tiempo / es aquél que se dedica todo el tiempo a su trabajo / es aquél que vive para eso / es aquél que está en su laboratorio de la mañana a la tarde / es aquél que busca en el microscopio / es aquél que buscará algo con un aparato).

El científico típico se dedica a buscar «algo», crear, inventar, descubrir (Cien t íf ico es aquél que está dándole, dándole, dándole, hasta que llega a algo, descubre algo o ve cosas sobre lo ya descubierto / es aquél que debe hacer un montón de cosas / es aquél al que no me lo imagino haciendo otras cosas / es aquél que también crea o inventa).

Hay similitud entre el científico típico y la caracterización que los entrevistados hacen de un científico del 1700: antes eran algunos pocos, unos ídolos, unos locos, confinados a un laboratorio.

\section{«.. yo así, locos como los vi a ustedes, no me lo ima- ginaba.»}

El paso por la facultad ha provocado algunos cuestionamientos a esta imagen que los mismos estudiantes re- conocen como previa (Cien t íf ic o es aquél al que ahora yo lo veo distinto a como lo veía antes cuando yo estaba en el secundario o en la primaria / es aquél que hay gente que aún le queda la idea de que están en un laboratorio solamente con fórmulas indistinguibles / es muy difícil que en mi carrera te encuentres un científico típico / es aquél al que no me lo imaginaba así, locos como los vi a ustedes / es aquél que empecé a pensar que no es así y menos en mi carrera).

Se manifiesta una nueva imagen más humanizada y cercana (Cient íf ico es aquél al que me imagino haciendo otra cosa además de trabajar todo el tiempo / es aquél que tiene un día típico normal como cualquier otro a la hora del «laburo» ${ }^{3}$ ) que se completa con ejemplos vivenciales (Cien tífico es aquél que más vale, va al campo antes que estar encerrado en un laboratorio).

Un contraste marcado con el científico típico, o el del 1700 , es que el «otro científico» no trabaja aislado (Cient ífico es aquél que ahora trabaja más en grupo / es aquél que es mejor que no esté aislado sino que a veces trabaje en grupo / es aquél que me lo imagino «laburando» con profesionales / es aquél que ahora «labura» con gente más preparada). Además este «otro» científico es descrito como: especialista en algo porque vos no podés abarcar todo por más que quieras; es preferible que sepan algo general pero que sepan más de algo en especial; es preferible que trabajen coordinando cosas, especialidades; ahora «labura» en cada campo específico.

\section{La ciencia}

\section{¿Qué es la ciencia?}

En los discursos de los estudiantes, la ciencia aparece como un conjunto de conocimientos (Ciencia es aquélla que es conocimiento) y como un conjunto de ideas (Cien cia es aquélla que es un conjunto de ideas / es aquélla que hoy también es pura mente) aunque no se agota en este campo (Cien cia es aquélla que va más allá de entender las cosas / es aquélla que es un poco más que pensar). Por otra parte, se destaca que es resultado de la actividad humana (Cien cia es aquélla que el hombre construye / es aquélla que el hombre trata de hacer para seguir acumulando conocimiento / es aquélla que trata de encontrar alguna solución a los problemas que se plantea el hombre, no que existen en la naturaleza).

\section{¿Cómo se hace ciencia?}

En cuanto al modo en el que se produce conocimiento en ciencia, los estudiantes mencionan que se siguen pasos metodológicos preestablecidos, a veces referidos como el método científico (Cien cia s son todas aquéllas que van a utilizar un método, van a seguir los mismos pasos para investigar algo / son todas aquéllas que van a seguir los pasos del método científico). Al referirse a 
estos pasos metodológicos, en algunos casos mencionan explícitamente: pregunta (Ciencia es aquélla en la que, cuando ven algo que ocurre, se preguntan por qué pasa), hipótesis (Cien cia es aquélla que para hacerla válidamente no podés largar una hipótesis así nomás), observación (Cien cia es aquélla que apunta primero a observar) y experimentación (Cien cia es aquélla que llega a conclusiones por medio de la investigación y la experimentación).

Se mencionan además características vinculadas a la sistematicidad en la toma de los datos (Cien cia es aquélla en la que lo que vos hacés lo tenés que dejar asentado con todos los pasos que hiciste, entonces, eso alguien lo puede volver a estudiar y ver si en realidad vos llegaste a una buena deducción o no), el análisis (Ciencia es aquélla donde se investiga parte por parte, hasta que lo saquen, y después juntarlo a ver qué pasa), el control de variables (Cien cia es aquélla en la que las condiciones en que vos estás trabajando las tenés controladas), incluso hasta la reproducción de un fenómeno (Cien cia es aquélla en la que, cuando ven algo que ocurre, tratan de reproducirlo hasta que lo logran).

Otra de las características mencionadas en los discursos para este proceso de producción es la necesidad de un lenguaje común (Cien cia es aquélla en la que todo está conocido con un solo nombre / es aquélla en la que todo el mundo usa una convención para que todo el mundo pueda hacer los mismos experimentos y llegar a ver qué conclusión sacaste).
Los estudiantes reconocen la existencia de diferentes formas de trabajar y, si bien se refieren a ellas como «métodos o metodologías» (Cien cia es aquélla que para estudiar usa métodos, prueba métodos, todas las metodologías diferentes), en ocasiones parecen confundirlas con técnicas, como puede apreciarse en el fragmento de entrevista presentado en el cuadro II.

\section{¿Cómo valida la ciencia el conocimiento?}

Con relación a este tema, los estudiantes ponen énfasis en distintos aspectos. En algunos discursos se expresa que el conocimiento se comprueba o se demuestra (Cie n cia es aquélla cuya diferencia con otras formas de conocimiento está en la comprobación y en la búsqueda / que si hacés una afirmación tenés que demostrarla bien / que para hacerla válidamente tenés que contrastarla con algo / en la que tienen que hacer un montón de pruebas).

Otros discursos se refieren a la imposibilidad de llegar a la verdad (Cien cia es aquélla que no llega a la verdad / que no creo que llegues a la verdad absoluta / que todo lo que dice no es verdad porque vos podés llegar a comprobar que es mentira). Se menciona el avance del conocimiento científico progresivamente hacia la «realidad» (Cien cia es aquélla que, a medida que avanza, las teorías van a ir acercándose a la realidad). La validación está a cargo de la comunidad de pertenencia en determinado momento histórico (Cien cia es aquélla que llega a lo más aceptable en ese momento / que llega a lo que en ese momento la mayoría de la gente acepta).

Entrevistador: ¿Cómo hace la ciencia para estudiar eso (= una cierta área, un campo)?

Alumna: Investiga, usa métodos, no sé, prueba métodos, todas las metodologías diferentes...

$E$ : ¿Hay muchas metodologías?

$A$ : Y, sí... [...] De la cabeza de cada tipo diferente.

$[\ldots]$

$E:$ ¿Y vos conocés alguna (= metodología)?

$[\ldots]$

A: No, no te puedo decir, sé que hay muchas. Yo usaría [...] un método científico. El simple de: tengo un objetivo, tengo esto, tengo lo otro... Pero porque todas las ciencias van a llegar a lo mismo en realidad, pero el método para investigar cada cosa, no, no sabría decírtelo.

$[\ldots]$

A: Todas las ciencias van a utilizar un objetivo, un método, un resul... todas van a seguir los mismos pasos, para investigar algo.

$E$ : ¿Y vos sabés cuáles son esos pasos?

A: Los del método científico.

$E$ : A ver, contámelo, dale.

$A$ : ¡No me podés preguntar eso!

$E$ : ¿Por qué?

A: Bueno, no sé, tener un objetivo, tener una hipótesis, tener una metodología de estudio, llegar a los resultados y a partir de los resultados sacar conclusiones.

$[\ldots]$

$E:$ ¿Y qué es lo que difiere en cada ciencia, entonces?

A: Y... el objetivo.

$E$ : Pero vos me decías que cada ciencia o cada persona tiene su método.

$A$ : Sí, pero yo me refiero a métodos de cómo estudiar cada cosa, no sé qué métodos hay, métodos en cuanto a materiales, método,

¿entendés?, a eso. 


\section{¿Cuáles son los fines de la ciencia?}

En los discursos de los estudiantes se identifican diversas finalidades de la actividad científica. En algunos casos proponen como finalidad para la ciencia la acumulación de conocimiento (Ciencia es aquélla que el hombre trata de hacer para seguir acumulando conocimiento, porque es poco lo que se puede conocer / es aquélla en la que podés ampliar muchísimo los conocimientos en todas las disciplinas). En otros casos, señalan como fin entender o comprender la naturaleza, el universo (Cien cia es aquélla que de acuerdo a sus principios entendés la naturaleza / es aquélla cuyo rol es entender, comprender y proyectar los fenómenos del universo / es aquélla que apunta a ver, entender y a comprender todos los procesos que pasan en la naturaleza), intervenir correctivamente si se encuentra un comportamiento anómalo (Cien cia es aquélla que apunta a tratar de mejorar lo que tiene comportamiento anómalo primero entendiéndolo), así como predecir (Cien cia es aquélla cuyo rol es poder predecir).

Otro grupo de respuestas refiere para la ciencia fines prácticos, en contraposición a otros campos del conocimiento (Ciencia es aquélla que, si no tuviera fines prácticos para el mismo hombre, sería algo filosófico), la resolución de problemas (Cien cia es aquélla que en ese momento es lo más próximo a lo que vos querés solucionar) y, en particular, el mejoramiento de la calidad de vida del hombre y del ambiente (Cien cia es aquélla cuyo fin puede ser trabajar para el mejoramiento del ambiente / es aquélla que hace el hombre cuando estudia la naturaleza para el bien del hombre / es aquélla que al hombre no le beneficiaría en nada eso de comprender y entender si no la utilizara en su beneficio / es aquélla cuyo fin puede ser trabajar para el mejoramiento de la calidad humana), llegando en algunos casos a justificar la subvención de la producción científica sobre la base de su utilidad (Cie n cia es aquélla que, si no fuera utilizada en beneficio del hombre, no habría un interés por parte del gobierno y cosas así para subvencionarla).

También se plantea, como objetivo de la actividad científica, el desarrollo de tecnología (Cie n cia es aquélla que va a estudiar cómo hacer una mejor tecnología) aun de la bélica (Cien cia es aquélla cuyo fin puede ser el avance de la tecnología bélica).

\section{¿Cuál es el valor de la ciencia?}

Asociadas a los discursos sobre los fines de la ciencia, algunos estudiantes expresan valoraciones positivas (Cien cia es aquélla que es muy importante / es aquélla que es buena porque te permite ampliar conocimientos / es aquélla que es buena porque te permite ampliar las fronteras que vos tenías). Sin embargo, este juicio se relativiza (Cien cia es aquélla que es buena hasta cierto punto) según para qué se la utilice y quiénes lo hagan (Cien cia es aquélla que es buena según qué manejo que se le dé a la tecnología / es aquélla que es una cosa buena según quien la use / es aquélla que es buena según qué opinión tenga el que la está usando).
En algunos discursos se hace referencia a este uso como una manipulación (Ciencia es aquélla que en muchos momentos de la historia fue manipulada / es aquélla cuya manipulación podría haber sido una constante / es aquélla que en muchos momentos fue usada), reconociendo como sujetos de la misma a diferentes actores de la comunidad en general con intereses diversos, tales como políticos (Cien cia es aquélla que fue usada por política), económicos (Cien cia es aquélla que está manipulada por la gente que tiene los medios como para bancar ${ }^{4}$ a los científicos) o bélicos (Cien cia es aquélla que fue usada en casos de guerra).

\section{La ciencia a través del tiempo}

Los estudiantes caracterizan a la ciencia identificando su dinámica: afirman que se construye (Cien cia es aquélla que se construye constantemente) aunque, en esencia, no cambia (Cien cia es aquélla que es siempre la misma a lo largo de la historia); hablan de su avance y de su retroceso (Cien cia es aquélla que siempre avanza aunque puede tener un retroceso que es un aporte / es aquélla que es un proceso indefinido en que constantemente estás avanzando en el conocimiento, estás abriendo fronteras), del cambio en la forma de hacer ciencia (Cien cia es aquélla que cambia la forma de hacerse a lo largo del tiempo) y del cambio en sus fines (Cien cia es aquélla cuyos fines han cambiado porque cada época tiene su pensamiento que lo rige / es aquélla cuyo rol cambió a lo largo de la historia).

Uno de los cambios que se mencionan para la ciencia a lo largo del tiempo es su apertura a sectores de la comunidad anteriormente excluidos ( $\mathrm{Cien}$ cia es aquélla que antes se la veía como algo más reservada para elegidos / es aquélla que ahora está abriéndose más, está saliendo un poco más a lo que es la gente que no hace ciencia / es aquélla que ya no es tanto una cosa para elegidos / es aquélla que todo el mundo hace salvo que no tenga el más mínimo interés de conocer nada).

\section{¿Cuál es la relación entre la ciencia y la tecnología?}

En los discursos de los estudiantes se plantea la relación entre la ciencia y la tecnología desde enfoques diferentes.

Algunos proponen que la ciencia crea a la tecnología (Cie n cia es aquélla que el hombre aplicó para crear tecnología / es aquélla que, al ir haciéndose, se iban inventando cosas, o sea la tecnología / es aquélla que va a estudiar cómo hacer una mejor tecnología) e incluso que debe solucionar problemas derivados de la misma (Cien cia es aquélla que se tiene que aplicar para solucionar el problema que puede ocurrir con la tecnología).

Otros sostienen que la ciencia y la tecnología son interdependientes (Cien cia es aquélla que, si no avanza, no avanza la tecnología / es aquélla que va de la mano de la tecnología / es aquélla que aporta tanto a la tecnología como la tecnología a la ciencia). 
También se plantea la importancia de la tecnología para el avance de la ciencia (Cien cia es aquélla que está ayudada con la tecnología / es aquélla de la cual algunas partes las podés estudiar con tecnología avanzada) y la producción de conocimiento (Con ocimien t o Cient íf ico es aquél que, si no hay la tecnología, se estanca / se acelera con el avance de la tecnología / se puede lograr por otra forma sin tecnología pero lleva su buen tiempo / se amplía rápido porque la tecnología avanza muy rápido / la tecnología influiría en acelerar).

Finalmente, en otros discursos se rescata la posibilidad de hacer ciencia independientemente de la tecnología (Cien cia es aquélla que antes se hacía y no tenían tecnología / es aquélla en la que hay un poco más de tecnología, hay un poco más de cosas [herramientas] para descubrir pero todos llegan a lo mismo).

\section{La ciencia y yo}

En algunos discursos, los estudiantes se mencionan a sí mismos, aclarando su falta de experiencia en este campo (Cien cia es aquello en lo que yo no estuve adentro / es aquello que veo medio desde afuera) o manifestando sentirse inmersos en un proceso (Cien cia es aquélla que todavía es medio difícil de decir cómo es al no estar muy metida).

\section{El conocimiento científico: «No sé cómo explicarte cómo saber si es científico o no.»}

\section{¿Cómo reconocer el conocimiento científico?}

Cuando los estudiantes explicitan qué criterios utilizan para reconocer un conocimiento científico se refieren a aspectos metodológicos, al sustento lógico y a un criterio de autoridad.

Al referirse a los aspectos metodológicos (Conocimient o Cient ífico es aquél que sigue ciertos pasos o cumple con ciertas reglas), ponen especial énfasis en la experimentación (Conocimient o Cient ífico es aquél que está probado experimentalmente y se puede repetir ese experimento y siempre llegás a los mismos resultados y conclusiones / es aquél que está probado experimentalmente, siempre que se pueda / es aquél que, cuando no se experimenta, deja de ser científico / es aquél que, cuando no lo probás o no hacés nada por probarlo, deja de ser científico).

Por otra parte, los estudiantes manifiestan la importancia del sustento lógico en el conocimiento científico (Con o cimien t o Cien $t$ íf ic o es aquél que tendrías que poder explicar lógicamente / es aquél que tiene sustento lógico / es aquél que, si no tiene sustento lógico, es como volver al tema de la fe).

El otro criterio explicitado, más operativo, se refiere a un criterio de autoridad considerando cuál es la fuente o quién es la persona que lo enuncia (Conocimient o Cient ífico es aquél que reconozco porque la gente que investigó son científicos / es aquél que, para saber si es científico o no, tenés que ver a la persona que lo investigó también / es aquél que, si viene Blanca Curi ${ }^{5}$ a decirme alguna cosa, capaz que no le creo).

Una característica mencionada del conocimiento científico es la de proporcionar explicaciones racionales, en contraposición al conocimiento religioso basado en la fe (Conocimient o Cient íf ico es aquél donde no te quedan tantas cosas libradas a que son así porque son así / es aquél en el que no te quedan tantas cosas que son así porque tenés que tener fe / es aquél que vos te enterás de que hay cosas que pasan, te enterás por qué pasan y todo tiene una explicación / es aquél que, cuando te cierra todo, generalmente te convence).

Finalmente al referirse a estas cuestiones, los estudiantes usan algunos términos (comprobación, validación lógica, demostración) sin llegar a delimitar sus alcances conceptuales, tal como se evidencia en el diálogo presentado en el cuadro III.

\section{ANÁLISIS DE LOS RESULTADOS Y DISCUSIÓN}

Las imágenes de científico, de ciencia y de conocimiento científico que presentan los estudiantes son complejas, dinámicas y parecen nutrirse de diversas fuentes. Las consideramos complejas debido a que están integradas por imágenes parciales, diferentes e incluso contrapuestas en algunos aspectos. Su grado de elaboración difiere en cada caso (científico, ciencia, conocimiento) y se encuentran en un proceso de cambio, según lo reconocen los mismos estudiantes.

Alumno: Para la ciencia, supongo que también es necesario comprobarlo [el hecho]; en cambio, para las otras [formas de conocimiento], no.

Entrevistador: ¿Cómo es el tema de la comprobación?

A: Ja, ja, ja.

$E$ : Claro, por eso te preguntaba. ¿Cómo te imaginás eso?

$A$ : Nunca me puse a pensar. 
La imagen de científico es la que se recorta más claramente; su caracterización se efectúa a partir de pocas variables recurrentes, así como de la utilización de la oposición antes lo veía y ahora lo veo. Interpretamos que este grado de elaboración puede relacionarse con la vivencia en el ámbito universitario, donde sus docentes son científicos. Los estudiantes pueden allí confrontar su imagen previa con quien está al frente de la clase (yo así, locos como los vi a ustedes, no me lo imaginaba). La imagen resultante presenta una parte construida desde un imaginario que completa lo que no conocen en forma directa, ya que, si bien los estudiantes ven al científico, no participan del contexto de producción científica.

Esta imagen presenta características recortadas del «científico típico»o «de antes» y de este «otro científico» con el que han tomado contacto. Es más elaborada que la que aparece en la bibliografía previa (Manassero y Vázquez, 2001) debido a que el científico aparece más humanizado. Sin embargo, sigue siendo ingenua: se encuentra relativamente aislado, no suele considerarse a la comunidad científica de la que forma parte y menos aún al financiamiento y a la política científica.

En todos los casos, el científico está delineado con cualidades positivas. La imagen del «científico típico»se diferencia del estereotipo social del «científico chiflado» que aparece en los medios de comunicación y que suele mencionarse en la bibliografía (Manassero y Vázquez, 2001). Éste presenta características negativas: es malvado, insano en ocasiones, insensible, frío, cerebral, malhumorado, obsesionado por alcanzar sus objetivos a cualquier precio. En nuestro estudio, el apelativo de «loco» se refiere más bien a poco convencional o excéntrico, pero no refleja actitudes negativas.

Una encuesta realizada en Capital Federal y Gran Buenos Aires a personas con estudios secundarios completos (Ciencia Hoy, 1998) evidencia la creencia de que a los científicos los mueven intereses genuinos por conocer la realidad, aunque el segmento de población que corresponde a 18-20 años muestra desconfianza respecto de las motivaciones de los científicos. La diferencia entre estos resultados y los del presente trabajo podrían deberse al recorte particular de la población de nuestro estudio, integrada por personas que han elegido estudiar carreras científicas.

En oposición a la imagen de científico, la imagen de ciencia aparece menos precisa y se define desde una diversidad de variables. Los estudiantes manifiestan verla medio desde afuera porque no estuve adentro, y todavía es medio difícil de decir cómo es al no estar muy metida. Esto se refiere tanto a su posición actual como a su proyección como investigadores. Es vista como un cuerpo de conocimientos que crece continua y acumulativamente, ya sea por descubrimiento o por construcción. El avance de la ciencia es inexorable porque si bien puede sufrir un retroceso [...] eso es un aporte.

Con respecto a la forma en que se hace ciencia, los estudiantes se refieren al «método científico», descripto como una serie de pasos a seguir en el desarrollo de una investigación. Esta misma descripción ha sido encontrada en libros de texto (Solbes y Traver, 1996) y en el discurso de docentes de diferentes niveles de enseñanza (De La Plaza y Menegaz, 2001; Cappannini et al., 1997) y de estudiantes universitarios (Cappannini et al., 1996). En nuestro estudio encontramos además que los estudiantes caracterizan la forma en que se hace ciencia por la sistematicidad, el análisis, el control de variables y el lenguaje común.

La gran mayoría (93\%) de la población encuestada por Ciencia Hoy (1998) identifica la ciencia con la búsqueda de conocimiento en alguna área de la realidad natural o social mediante la obtención de información o realización de experimentos, de acuerdo con un ítem preestablecido. En líneas generales, esta opinión coincide con el discurso de nuestros estudiantes. También hay coincidencia en la valoración de la ciencia que no es buena ni mala en sí misma, sino que depende del uso que se le dé. Una diferencia hallada es el énfasis que la población encuestada pone en la idea de progreso y desarrollo en asociación con la ciencia, seguida por la asociación con la investigación y con la educación. En nuestro estudio, los términos progreso y desarrollo surgen asociados a la ciencia para describir su dinámica interna y no en relación con la sociedad.

Los fines de bienestar de la comunidad y elaboración de explicaciones coinciden con otros trabajos (Aikenhead et al., 1987; Petrucci y Dibar Ure, 2001). Si bien en la mayoría de los discursos se plantea una relación entre ciencia y tecnología, apenas se menciona el desarrollo tecnológico como finalidad específica de la ciencia. Este resultado difiere del obtenido por Aikenhead y otros (1987) con estudiantes secundarios de Canadá, según los cuales la ciencia aumenta el bienestar de la comunidad mediante la manufactura de artefactos. Esta diferencia puede deberse a que en nuestro país estos artefactos suelen importarse. Otro rasgo particular que surge de nuestro estudio es la importancia atribuida al cuidado del medio ambiente, que aparece en sí mismo señalado como un fin de la ciencia. Debe tenerse en cuenta que se trata de estudiantes que han elegido una carrera de ciencias naturales, entre los cuales un $80 \%$ manifiesta interés por el cuidado de la naturaleza, implicándose de un modo directo y personal con esta tarea al ingresar a la facultad (DDCN, 1994).

En relación con los criterios que los estudiantes señalan para considerar científico a un conocimiento, aparecen los aspectos metodológicos, el criterio de autoridad, la experimentación y el sustento lógico. Los aspectos metodológicos y el criterio de autoridad coinciden con los resultados de un trabajo previo con un grupo de docentes preuniversitarios (Cordero et al., 2001), lo cual nos remite a proponer el ámbito escolar como posible fuente de esta imagen. La mención de la «experimentación» como criterio merece una consideración particular. Por un lado, en muchas de las disciplinas desarrolladas en la facultad, la validación de los conocimientos que son objeto de enseñanza no involucran experimentación. Por otro, a la altura de la carrera en la que se encontraban los estudiantes al ser entrevistados, las prácticas experimen- 
tales se reducían a una única asignatura auxiliar. Surge, entonces, como interrogante cuál es el origen de esta noción y resultaría de interés indagar el discurso de los docentes en el aula en relación con este tema.

Desde otro enfoque, podemos decir que los estudiantes usan algunos términos sin llegar a delimitar sus alcances conceptuales. Algunos de los términos en los que hemos detectado confusiones o imprecisiones son: comprobación, validación lógica, demostración, por un lado, y metodología, método y técnica, por otro. Esto nos sugiere que los estudiantes están comenzando a emplear un lenguaje nuevo, incorporando en su discurso términos propios del contexto de formación por considerarlos característicos del campo científico al que desean acceder.

Finalmente, consideramos que la existencia de imágenes diversas, heterogéneas, dinámicas y parciales tiene la virtud de otorgar versatilidad para actuar en distintos contextos. Esta condición pasa a ser una herramienta facilitadora en el momento de formación, ya que un mismo sujeto puede alternar roles diversos en distintos grupos de pertenencia: al participar en grupos de estudio como estudiante, en reuniones de cátedra como auxiliar docente, en prácticas de investigación como pasante o becario, o en otros grupos extraacadémicos.

\section{REFLEXIONES EMERGENTES}

Como se ha expuesto, los resultados obtenidos muestran diferencias en el grado de elaboración de las definiciones de científico, ciencia y conocimiento científico. Al preguntarnos sobre la naturaleza de estas diferencias, así como sobre su posible implicancia en el proceso de formación de los estudiantes y su inserción laboral, recurrimos al concepto de representación social como herramienta de análisis. Como ya mencionamos, las representaciones son imágenes que condensan significados y se constituyen en sistemas de referencia que permiten interpretar y clasificar, implicando una relación sujeto-objeto. Las categorías establecidas por el sujeto no sólo permiten la interpretación del objeto sino que condicionan el vínculo y, por reflejo, al propio sujeto. En este marco interpretamos que las representaciones de los estudiantes sobre los objetos ciencia y científico expresan contenidos, sentidos y valoraciones pero también condicionan su autopercepción como estudiantes y como futuros científicos.

Las representaciones de los estudiantes con respecto al científico nos sugieren cómo se posicionan ellos en cuanto a «ser científicos» y en este sentido orientan y condicionan su proyección como futuros investigadores. Cuando describen al científico como desinteresado, que no manipula pero puede ser manipulado, que aspira a hacer las cosas bien, desea mejorar el mundo, trata de progresar, etc., se están proyectando a sí mismos y describiendo la imagen que va a orientar su formación.

Esta representación da cuenta de la efectiva iniciación de los sujetos en el proceso de inclusión en el campo científico al cual quieren pertenecer. Como Bourdieu (2000) señala, este interés «puro», desinteresado, propio del campo científico, es un interés en el desinterés, conveniente en las economías de bienes simbólicos, en las que lo «redituable» es el desinterés. Según este autor, el campo científico produce una forma particular de illusio, definiendo el interés científico como un interés desinteresado, gratuito, a diferencia de formas vigentes en el campo económico. Sin embargo, «los sabios son interesados, tienen ganas de llegar primeros, de ser los mejores, de brillar» (Bourdieu, 2000, p. 84). La sublimación implicada en esta illusio, tácitamente exigida a todo ingresante, define los objetos de interés capaces de merecer la inversión e induce a admitir que el juego científico vale la pena ser jugado (Gutiérrez, 1995; Bourdieu, 2000).

Otro aporte al presente análisis proviene de la perspectiva de Foucault (1998), para quien «los códigos fundamentales de una cultura -los que rigen su lenguaje, sus esquemas perceptivos, sus cambios, sus técnicas, sus valores, la jerarquía de sus prácticas-fijan de antemano para cada hombre los órdenes empíricos con los cuales tendrá algo que ver y dentro de los que se reconocerá». Según esta visión, las categorías implícitas en una representación demarcan lo que es posible ser pensado. En este sentido, a partir de las representaciones de nuestros estudiantes, parece que no es posible pensar en un investigador interesado o cómplice, en una ciencia ligada por decisión propia a intereses externos, ni en un conocimiento científico en el que la fe, las subjetividades, los intereses o las creencias estén presentes. En las representaciones de los estudiantes hay dos grandes ausencias: la comunidad científica y la sociedad en general. El investigador queda así aislado, excluido de la trama vincular ciencia-sociedad. Esta situación paraliza: no es posible pensarse dentro de una comunidad o grupo de pertenencia que permita dar cuenta del sistema, porque no hay sistema al cual cuestionar. Así, la falta de categorías descriptivas sobre ciencia, el desconocimiento de la existencia de un sistema estructurado que regula la actividad científica y la visión ingenua del científico favorecen la incorporación acrítica de los estudiantes al sistema científico. De este modo se facilita la apropiación por parte del sujeto del modelo hegemónico, garantizándose su reproducción.

Análogamente a las ideas actuales sobre la formación inicial de profesores (Mellado y González, 2000) de no mediar instancias de reflexión explícita y trabajo crítico sobre estas representaciones durante la formación de científicos, cabe esperar que las mismas no sufran modificaciones. De esta manera, sin espacios que promuevan la reflexión sobre el modelo de ciencia y producción científica en relación con la comunidad, el sistema se reproduce y los nuevos científicos sólo producen más de lo mismo.

Podemos encontrar un aporte superador de esta situación en la perspectiva que ofrecen las llamadas «teorías de la resistencia» (Da Silva, 1995, 1999) o «de la oposición» (Kemmis, 1988). Encuadrados en esta línea, Giroux y McLaren (1989) plantean que en la institución educativa y el currículo existen mediaciones y acciones que 
pueden trabajar contra la reproducción de las estructuras hegemónicas, recuperando la valoración del hecho educativo como espacio para la oposición y la resistencia. De este modo el rol de los profesores se redimensiona como el de «intelectuales transformadores», propuesto por Giroux. Este agente facilita y posibilita la construcción social de significados en los espacios de enseñanza desde los propios actores.

A pesar de su postura estructuralista, Bourdieu y Wacquant (1992) efectúan un desarrollo conceptual en relación con el habitus que va en la misma dirección que lo expresado en el párrafo anterior. Si bien el habitus constituye un sistema de disposiciones durables, estas disposiciones no son inmutables. Es posible, entonces, introducir cambios a través de un proceso de autosocioanálisis, un análisis reflexivo de los condicionantes objetivos de las propias prácticas, mediante el cual el sujeto pueda explicitar posibilidades y limitaciones, libertades y necesidades de su habitus. Así, pueden modificarse las percepciones y representaciones y elaborar estrategias diferentes de acción. Esto es posible «al precio de un trabajo constante y metódico de explicitación. A falta de un análisis de esas determinaciones sutiles que operan a través de las disposiciones, uno se hace cómplice de la acción inconsciente de las disposiciones, que es ella misma cómplice del determinismo» (Bourdieu y Wacquant, 1992, pp. 111-112).

\section{REFERENCIAS BIBLIOGRÁFICAS}

AIKENHEAD, G. S., FLEMING, R. W. y RYAN, A. G. (1987). High school graduates' beliefs about science-technologysociety I: Methods and issues on monitoring student views. Science Education, 71(2), pp. 145-161.

BOURDIEU, P. (1991). El sentido práctico. Madrid: Taurus.

BOURDIEU, P. (2000). Los usos sociales de la ciencia. Buenos Aires: Ediciones Nueva Visión.

BOURDIEU, P. y WACQUANT, L. (1992). Réponses. París: Seuil.

CAPPANNINI, O., LÚQUEZ, V., MENEGAZ, A., SEGOVIA, R. y VILLATE, G. (1996). Introducción de conceptos de metodología científica en un curso de física de grado. Memorias del III SIEF, pp. 193-199. Córdoba (Argentina).

CAPPANNINI, O., CORDERO, S., MENEGAZ, A. SEGOVIA, R., VILLATE, G. y MORDEGLIA, C. (1997). Metodología científica en el aula: una experiencia innovadora en la formación docente. Congreso Internacional de Enseñanza de las Ciencias. Murcia.
Finalmente y en relación con los últimos párrafos, pretendemos que los resultados de este trabajo sean una contribución para el análisis crítico de las prácticas de enseñanza y aprendizaje.

\section{AGRADECIMIENTOS}

Son muchas las personas a quienes queremos dar las gracias. Nombraremos a los estudiantes, por su buena disposición; a Celia Dibar, por su orientación durante la investigación; a Virginia Ceirano, por su orientación metodológica durante el análisis semiótico y la lectura crítica del trabajo; a Silvina Cordero, por la revisión del manuscrito, las sugerencias y la enriquecedora discusión; y a Javier Perales, por su valiosa lectura crítica. Finalmente agradecemos a todos los integrantes del GDC su paciencia y contención.

\section{NOTAS}

${ }^{1}$ Jorge Luis Borges, «El idioma analítico de John Wilkins», en Otras inquisiciones.

${ }^{2}$ Personaje de historieta infantil, que usa enormes gafas y se caracteriza por su bondad, corrección, honestidad, etc.

${ }^{3}$ Término lunfardo que deriva del italiano lavoro: «trabajo».

${ }^{4}$ Término lunfardo: «respaldar, financiar».

${ }^{5}$ Astróloga que suele aparecer en la televisión.
CEIRANO, V. (2000). Las representaciones sociales de la pobreza: una metodología para su estudio. Cinta de Moebio. Revista Electrónica de Epistemología en Ciencias Sociales, 9, pp. 1-17.

CIENCIA HOY. Nota especial. (1998). ¿Qué piensan de la ciencia los argentinos?, 8(48). www.ciencia-hoy.retina.ar/ hoy48/encu01.htm.

CORDERO, S., DUMRAUF, A.G., MENEGAZ, A., MENGASCINI, A. y MORDEGLIA, C. (2001). Saberes y formación docente: imágenes docentes acerca de la metodología científica y de la célula. Manuscrito.

DA SILVA, T. (1995). Escuela, conocimiento y curriculum. Ensayos críticos. Buenos Aires: Miño y Dávila Editores.

DA SILVA, T. (1999). Documentos de identidad. Una introducción a las teorías del curriculum. Belo Horizonte: Auténtica.

DDCN (Departamento de Didáctica de las Ciencias Naturales) (1994). Informe de resultados del curso introductorio a la Facultad de Ciencias Naturales. Universidad Nacional de La Plata. 
DE LA PLAZA, S. y MENEGAZ, A. (2001). Las herramientas científicas en el niño pequeño. Una propuesta de formación docente desde la experiencia en Argentina, en Puché de Navarro, R., Colinvaux, D. y Dibar Ure, M.C. El niño que piensa: un modelo de formación de maestros, pp. 215-248. Santiago de Cali: Artes gráficas del Valle Editores.

DRIVER, R., LEACH, J., MILLAR, R. y SCOTT, P. (1996). Young People's Images of Science. Londres: Open University Press.

ERICKSON, B.H. y NOSANCHUK, T.A. (1977). Understanding Data. Londres: Open University Press.

FOUCAULT, M. (1998). Las palabras y las cosas. (26a. ed. cast.) México: Siglo x xi.

GIROUX, H. y McLAREN, P. (eds.) (1989). Critical pedagogy, the state and cultural struggle. Nueva York: University of New York Press.

GLASSER, B. y STRAUSS, A. (1968). The Discovery of Grounded Theory: Strategies for Qualitative Research. Londres: Weidenfeld y Nicholson.

GUICHARD, J. (1995). La escuela y las representaciones de futuro de los adolescentes. Capítulo III: Hábitos, representaciones sociales y categorizaciones. Barcelona: Laertes.

GUTIÉRREZ, A. (1995). Pierre Bourdieu. Las prácticas sociales. Posadas: Editorial de la Universidad Nacional de Misiones.

JODELET, D. (1986). La representación social: fenómenos, concepto y teoría, en Moscovici, S. Psicología Social II, pp. 469-494. Barcelona: Paidós.
KEMMIS, S. (1988). El curriculum: más allá de la teoría de la reproducción. Madrid: Morata.

KOULADIS, V. y OGBORN, J. (1989). Philosophy of science: an empirical study of teachers' views. International Journal of Science Education, 11(2), pp. 173-184.

LEDERMAN, N. G. (1992). Students' and Teachers' Conceptions of the Nature of Science: A Review of the Research. Journal of Research in Science Teaching, 29(4), pp. 331-359.

LEDERMAN, N.G., WADE, P.W. y BELL, R.L. (1998), Assessing the Nature of Science: What is the Nature of Our Assessments? Science and Education, 7, pp. 595-615.

MAGARIÑOS DE MORENTÍN, J.A. (1993). La semiótica de enunciados. La Plata: IICS, UNLP.

MAGARIÑOS DE MORENTÍN, J.A. (1996). Los fundamentos lógicos de la semiótica y su práctica. Buenos Aires: Edicial.

MANASSERO, M.A. y VÁZQUEZ, Á. (2001). Actitudes de estudiantes y profesorado sobre las características de los científicos. Enseñanza de las Ciencias, 19(2), pp. 255-258.

MELLADO JIMÉNEZ, V. y GONZÁLEZ BRAVO, T. (2000). La formación inicial del profesorado de ciencias, en Perales Palacios, F. J. y Cañal de León, P. Didáctica de las ciencias experimentales, pp. 535-555. Alcoy: Marfil.

PETRUCCI, D. y DIBAR URE, M.C. (2001). Imagen de la ciencia de estudiantes universitarios: una revisión y resultados. Enseñanza de las Ciencias, 19(2), pp. 217-229.

SOLBES, J. y TRAVER, M.J. (1996). La utilización de la historia de las ciencias en la enseñanza de la física y la química. Enseñanza de las Ciencias, 14(1), pp. 103-112. 


\begin{abstract}
ANEXO
A continuación se transcriben los segmentos de los guiones de las entrevistas que dieron origen a los datos analizados en este trabajo.
\end{abstract}

\title{
Entrevista de 1996
}

- Describí como te imaginás que trabaja un científico.

- ¿Qué relación te parece que hay entre la ciencia y la tecnología?

- ¿Hay alguna diferencia entre decir que una teoría es válida o decir que es verdadera?

- ¿Qué relación ves vos que hay entre ciencia y verdad pensando a la ciencia como una forma de conocimiento, como el arte, la religión, la magia...?

- En las respuestas a la pregunta* «Cuáles son los fines de la ciencia?», aparecen expresiones como «descubrir la verdad», «avance», «progreso» o «conocer más». Esas palabras me hacen pensar que esos alumnos tienen la idea de que con el tiempo hay un aumento inexorable del conocimiento científico. Otros hablan de que «el desarrollo del conocimiento sufre marchas y contramarchas». Tengo dudas de si eso es realmente lo que ellos estaban pensando. ¿A vos que te parece? ¿Vos afirmarías eso?

- Con respecto a la pregunta* ¿Las teorías científicas cambian? ¿Cómo? ¿Por qué?», hay algunas respuestas que no entiendo, o parecen confusas o incompletas, por ejemplo, «Sí, hasta que se demuestra lo contrario.» Otras son más claras, como: «Porque todo es relativo, el conocimiento no es supremo, todo lo que no es supremo está sujeto a errores.» Lo que quiero que hagamos es esto: yo te voy a dar algunas respuestas y vos me decís qué opinás de cada una y luego numerala, 1 a la que estás más de acuerdo, 2 a la siguiente... y así.

- Cambian cuando una es reemplazada por otra mejor.

- Cambian cuando una teoría es refutada.

- Cambian cuando se produce una revolución científica.

- Porque existen diferentes puntos de vista, principios o cosmovisiones que cambian con el tiempo.

- Porque todo está puesto a revisión, nadie tiene la verdad absoluta, toda teoría es refutable.

- Respecto a la pregunta “Cuando te encontrás ante un conocimiento dado, ¿cómo te das cuenta de si es científico o no?», hubo muchos que no la contestaron, entonces lo que quiero hacer es esto: te doy otra hoja y me comentás qué te parece cada opción y con cuál estás más de acuerdo:

Un conocimiento es científico:

- Si está probado experimentalmente.

- Si sigue ciertos pasos o cumple ciertas reglas.

- Si tiene sustento lógico.

- Ninguna de las anteriores. ¿Cuál?

- No sé.

¿Cambió el rol de la ciencia a lo largo de la historia?

* Se refiere a preguntas que formaban parte de un cuestionario previamente contestado por los entrevistados. El diseño del cuestionario y los resultados obtenidos se encuentran en Petrucci y Dibar (2001).

\section{Entrevista de 1998}

- ¿Cómo ves vos a la naturaleza, al mundo? (Preguntas alternativas: ¿Cómo definirías qué es la naturaleza?, ¿con qué adjetivos? Cuando pensás en naturaleza, ¿en qué pensás?, ¿qué imagen te viene a la cabeza?)

- Y la ciencia, ¿cómo funciona en ese esquema?

- Y la tecnología, ¿dónde entra en ese proceso?, ¿cómo?

- ¿De dónde sale la tecnología? ¿A qué se debe el avance tecnológico?

- Si agarrás una revista que es una publicación científica, medianamente confiarías en lo que dice ahí; pero, si agarrás una revista que vos sabés que es medio sospechosa, ¿cómo hacés para decidir si vas a confiar en lo que está diciendo o no? 
